\title{
Evaluation of risk factors in acute myocardial infarction patients admitted to the coronary care unit, Tripoli Medical Centre, Libya
}

A.R.Abduelkarem, ${ }^{7}$ H.J. El-Shareif ${ }^{2}$ and S.I. Sharif ${ }^{3}$

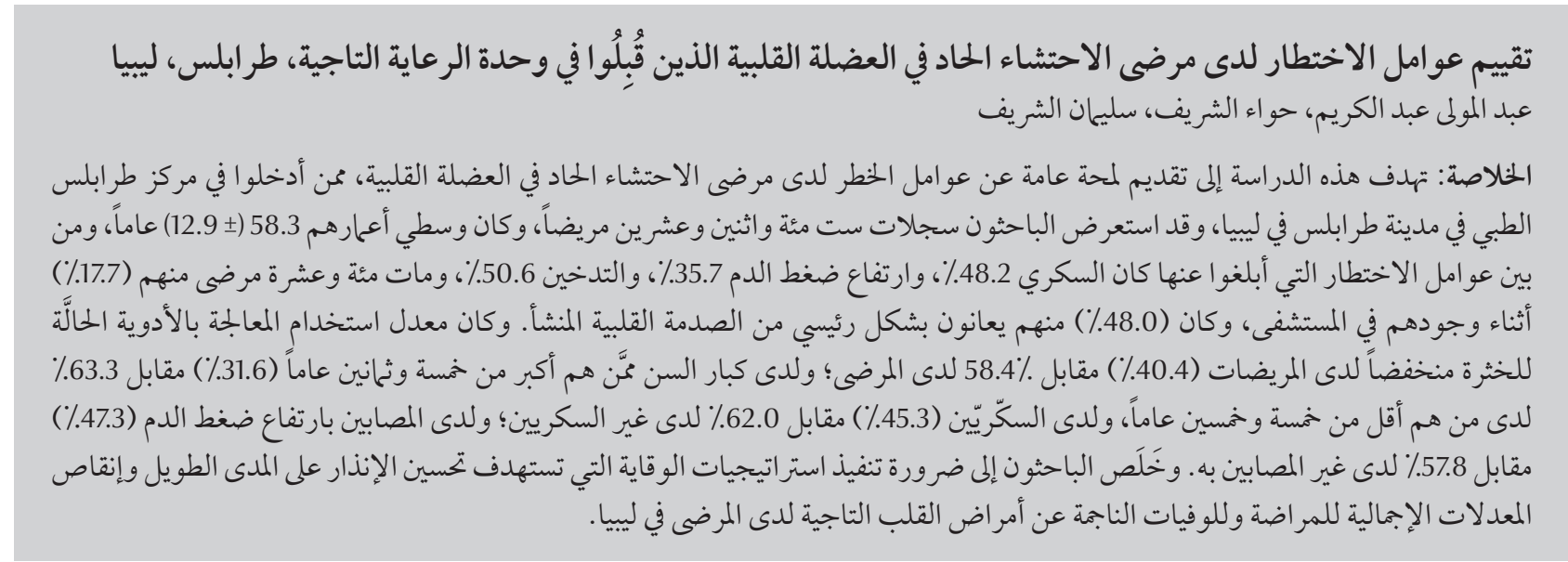

ABSTRACT The aim of this study was to provide an overview of the risk factors for acute myocardial infarction in patients attending Tripoli Medical Centre, Libya. Records were reviewed for 622 patients with a mean age of 58.3 (SD 12.9) years. Diabetes mellitus (48.2\%), hypertension (35.7\%) and smoking (50.6\%) were among the risk factors reported. There were 110 patients (17.7\%) who died during hospitalization, mainly suffering cardiogenic shock (48.0\%). The rate of use of thrombolytic therapy was low in patients who were female $(40.4 \%$ versus $58.4 \%$ for males), older age (31.6\% for those $>85$ years versus $63.3 \%$ for patients $<55$ years), diabetics $(45.3 \%$ versus $62.0 \%$ for non-diabetic patients) and hypertensives (47.3\% versus $57.8 \%$ for non-hypertensive patients). Prevention strategies should be implemented in order to improve the long-term prognosis and decrease overall morbidity and mortality from coronary artery disease in Libyan patients.

Évaluation des facteurs de risque chez des patients admis pour infarctus aigu du myocarde dans l'unité de soins aux coronariens du centre médical de Tripoli (Libye)

RÉSUMÉ L'objectif de la présente étude était de fournir une vue d'ensemble des facteurs de risque chez des patients séjournant au centre médical de Tripoli (Libye) pour un infarctus aigu du myocarde. Les dossiers de 622 patients âgés en moyenne de 58,3 ans (écart type 12,9) ont été étudiés. Le diabète sucré (48,2 \%), I'hypertension $(35,7 \%)$ et le tabagisme (50,6 \%) comptaient parmi les facteurs de risque signalés. Pendant leur séjour hospitalier, 110 patients sont décédés (17,7 \%), principalement d'un choc cardiogénique (48,0\%). Le taux d'utilisation d'un traitement thrombolytique était faible chez les patients de sexe féminin (40,4\% contre 58,4\% pour les patients de sexe masculin), les personnes âgées (31,6 \% pour les patients âgées de plus de 85 ans contre $63,3 \%$ pour les patients de moins de 55 ans), les diabétiques (45,3\% contre $62,0 \%$ pour les non diabétiques) et les hypertendus (47,3\% contre $57,8 \%$ pour les patients ne souffrant pas d'hypertension). Des stratégies préventives doivent être mises en œuvre afin d'améliorer le pronostic à long terme des patients libyens et de réduire la morbidité et la mortalité globales dues à la coronaropathie.

${ }^{'}$ Department of Clinical Pharmacy and Pharmacy Practice, College of Pharmacy and Health Sciences, Ajman University of Science and Technology Network, Ajman, United Arab Emirates (Correspondence to A.R. Abduelkarem: karem1961@hotmail.com).

${ }^{2}$ Department of Endocrinology, Tripoli Medical Centre, Al-Fateh University of Medical Sciences, Faculty of Medicine, Tripoli, Libya.

${ }^{3}$ Department of Pharmacology, College of Pharmacy, University of Sharjah, Sharjah, United Arab Emirates.

Received: 29/03/10; accepted: 20/09/10 


\section{Introduction}

Cardiovascular disease is a heterogeneous group of disorders that affect the heart and blood vessels. Coronary heart disease (CHD), in particular, is the main cause of premature death in many countries $[1,2]$. In Libya, as in many other African nations it is the number one cause of death [3]. In Africa, CHD accounted for $9.2 \%$ of deaths in 2001, principally due to hypertension, stroke, cardiomyopathy and rheumatic valve disease [4]. More recently, it has been concluded in one study in Benghazi that circulatory diseases were still the main cause of death in diabetics, with acute myocardial infarction (MI) at the top of the list [3].

The prevalence of acute MI as the first manifestation of ischaemic heart diseases is high in approximately 50\% to $70 \%$ of patients and is a common cause for hospital admission [5]. Several factors related to the severity of the disease have been identified, such as smoking [6], diabetes mellitus [7], systemic arterial hypertension [8], dyslipidaemia [1], the number of arteries impaired and degree of functional impairment of the left ventricle [9]. Furthermore, age, sex, obesity, heavy alcohol consumption and physical inactivity were all also recognized as contributory factors [1]. The risk factors associated with $\mathrm{CHD}$ are multifactorial and work synergistically. Genetic predisposition, sex (it is more common in males), family history of ischaemic heart disease (especially in a first-degree relative under 55 years), stroke, peripheral vascular disease and advanced age are recognized risk factors for the development of $\mathrm{CHD}$ over which there is little control $[10,11]$.

Many studies have been conducted on patients with acute MI, but little published information about acute MI in Libyan patients is available [3]. The present study was conducted with the goal of providing an insight into the demographic data, distribution of risk factors and clinical and laboratory findings of patients with acute MI at Tripoli medical centre.

\section{Methods}

\section{Setting and sample}

Tripoli medical centre is a public hospital with 1485 beds of which 68 beds are assigned for critical care services. The hospital is the main teaching hospital for the college of medicine of Tripoli University. Although it is a tertiary referral hospital, it operates an active primary care centre with a 24-hour emergency coverage accessible to anyone and from which appropriate patients are admitted to the hospital's medical wards. The average bed occupancy rate is $70 \%$.

The case records of all patients with the diagnosis of acute MI admitted to the coronary care unit in Tripoli medical centre between January 2006 and December 2008 were reviewed retrospectively. The following criteria were used for the diagnosis of acute MI: a clinical history of sudden chest pain, electrocardiogram (ECG) changes consistent with acute MI or characteristic changes in serum cardiac enzymes activity including: creatine kinase (CK), aspartate aminotransferase (AST), and lactate dehydrogenase (LDH) on 3 consecutive days after admission.

\section{Data collection}

For the purpose of the study, patient information related to age, sex, disease risk factors, clinical presentation, duration of symptoms prior to admission, and known history of diabetes, in addition to analysis of ECG and cardiac enzymes profile, was extracted from the patient's case notes. The main risk factors studied were: patient's sex, cigarette smoking (current and ex-smokers), medical history of diabetes or newly diagnosed hyperglycaemia occurring during hospitalization (fasting blood glucose $\geq 126 \mathrm{mg} / \mathrm{dL}$ or random blood glucose $\geq 200 \mathrm{mg} / \mathrm{dL}$ ), hypertension ( $\geq$ $140 / 90 \mathrm{mmHg}$ or on antihypertensive medication), history of hyperlipidaemia (total cholesterol $\geq 200 \mathrm{mg} / \mathrm{dL}$ or being on lipid lowering drugs), history of CHD and history of cerebrovascular accident.

\section{Statistical analysis}

Data were analysed using SSPS statistical package, version 10. Frequency distributions were generated and the chi-squared test was used to assess the significance of differences between categories. $P$-valued $<0.05$ were considered significant.

\section{Results}

There were 622 admissions to the coronary care unit during the study period. There were 471 patient records investigated for males (75.7\%) and 151 for females (24.3\%), giving a male to female ratio of $3.1: 1$. The mean age for male and female patients was 58.3 (SD 12.9) years (range 24-91 years) and 65.0 (SD 11.4) years (range 36-97 years) respectively. The ratio of patients $\geq 60$ years of age to those $<60$ was 1.0:1 in male and 3.3:1 in female patients. The peak age of occurrence of acute MI for males and females was 60-69 years (Table 1). The male to female ratio was 6.6: 1 in those $<60$ years of age and 2.1:1 in older patients.

\section{Risk factors}

Smoking, diabetes, hypertension and history of CHD were the most common cardiovascular risk factors in the sample studied. More than half (50.6\%) of both male and female patients were reported to be current smokers (smoking history was only available for 457 patients) and out of the 296 patients $17.5 \%$ were exsmokers and $62.6 \%$ were current smokers. Almost half of the pooled sample (48.2\%) were identified as having diabetes mellitus (type 1 or 2 unspecified). History of hypertension and $\mathrm{CHD}$ were reported in $35.7 \%$ and $21.7 \%$ respectively. However, both dyslipidaemia and 


\begin{tabular}{|c|c|c|c|c|c|c|}
\hline \multicolumn{7}{|c|}{$\begin{array}{l}\text { Table } 1 \text { Age and sex distribution of myocardial infarction patients at Tripoli } \\
\text { Medical Centre }\end{array}$} \\
\hline \multirow[t]{2}{*}{ Age (years) } & \multicolumn{2}{|c|}{$\begin{array}{c}\text { Males } \\
(n=417)\end{array}$} & \multicolumn{2}{|c|}{$\begin{array}{l}\text { Females } \\
(n=151)\end{array}$} & \multicolumn{2}{|c|}{$\begin{array}{c}\text { Total } \\
(n=622)\end{array}$} \\
\hline & No. & $\%$ & No. & $\%$ & No. & $\%$ \\
\hline$<50$ & 146 & 31.0 & 17 & 11.3 & 163 & 26.2 \\
\hline 50-59 & 84 & 17.8 & 18 & 11.9 & 102 & 16.4 \\
\hline $60-69$ & 138 & 29.3 & 53 & 35.1 & 191 & 30.7 \\
\hline 70-79 & 81 & 17.2 & 47 & 31.1 & 128 & 20.6 \\
\hline$>79$ & 22 & 4.7 & 16 & 10.6 & 38 & 6.1 \\
\hline
\end{tabular}

history of cerebrovascular accidents as CVD risk factors were reported in only 43 patients $(6.9 \%)$. Table 2 summarizes the distribution of cardiovascular risk factors among the pooled sample.

\section{Clinical presentation}

Clinical characteristics, in-hospital treatment and treatment at discharge of acute MI patients under investigation are summarized in Table 3.

Acute chest pain was the presenting complaint in 558 (89.7\%) patients. Other presenting symptoms included nausea and vomiting in 441 (70.9\%) and epigastric pain in 109 (17.5\%). Data on duration of symptoms prior to presentation at the hospital were available for 576 patients. In $35.9 \%$ of these cases the duration was $>12$ hours. Mean duration of stay in the coronary care unit was 4.0 (SD 2.9) days, range $0-28$ days. Of the $480(77.0 \%)$ patients who were discharged, 128 (26.7\%) had stayed in hospital for $<8$ days, 251 (52.3\%) had stayed for 8-14 days while 101 (21.0\%) patients had stayed $>14$ days. Eleven (1.8\%) patients had a cardiac arrest at presentation and 7 of these (63.6\%) died during the study period. Seventeen (2.7\%) the patients presented in cardiogenic shock, with a mortality rate of 13 (76.5\%). Acute pulmonary oedema was the presenting clinical feature in $23(3.7 \%)$ patients, 5 of whom (21.7\%) died.

All of the patients included in the study had abnormal ECG. The different ECG patterns at presentation are shown in Table 3. Furthermore, the $\mathrm{CK}$ value at presentation was more than the upper limit of the normal reference range ( 167 $\mathrm{IU} / \mathrm{L})$ in $514(82.6 \%)$ patients; the mean CK value was 1084 (SD 1144) $\mathrm{IU} / \mathrm{L}$ (range 21-7617 IU/L) in the patients studied. Elevated LDH levels

\section{Laboratory investigations}

at presentation were above the upper limit of the normal reference range (480 $\mathrm{IU} / \mathrm{L})$ in $443(71.2 \%)$ patients; the mean LDH value was 1034 (SD 839) (range 51-9182 IU/L).

\section{Management}

Aspirin, beta-blockers, streptokinase and $\mathrm{ACE}$ inhibitors were the most important drug or drug groups used by the patients under investigation in the hospital during the study period. Aside from cases that had contraindications for their use, the rate of use of thrombolytic therapy was low in certain groups of patients. These include female sex ( $40.4 \%$ compared with $58.4 \%$ for males), old age ( $31.6 \%$ for those $\geq 85$ years compared with $63.3 \%$ for patients $<55$ years), patients with diabetes (45.3\% compared with $62.0 \%$ for nondiabetic patients), and patients with hypertension (47.3\% compared with $57.8 \%$ for non-hypertensive patients).

\section{Discussion}

CHD continues to be one of the major causes of morbidity and mortality among women as well as men in many countries $[1,5]$. CHD is much less frequent in premenopausal women than in age-matched men [12]. This essentially shifts the incidence curves for women by 5-10 years compared with men [13]. Acute MI below the

\begin{tabular}{|c|c|c|c|c|c|c|}
\hline \multirow[t]{2}{*}{ Risk factor } & \multicolumn{2}{|c|}{$\begin{array}{c}\text { Males } \\
(n=417)\end{array}$} & \multicolumn{2}{|c|}{$\begin{array}{l}\text { Females } \\
(n=151)\end{array}$} & \multicolumn{2}{|c|}{$\begin{array}{c}\text { Total } \\
(n=622)\end{array}$} \\
\hline & No. & $\%$ & No. & $\%$ & No. & $\%$ \\
\hline Diabetes & 202 & 42.9 & 98 & 64.9 & 300 & 48.2 \\
\hline Hypertension & 147 & 31.2 & 75 & 49.7 & 222 & 35.7 \\
\hline History of coronary artery disease & 100 & 21.2 & 35 & 23.2 & 135 & 21.7 \\
\hline History of cerebrovascular accident & 22 & 4.7 & 10 & 6.6 & 32 & 5.2 \\
\hline \multirow[t]{2}{*}{ History of hyperlipidaemia } & 11 & 2.3 & 0 & 0.0 & 11 & 1.8 \\
\hline & \multicolumn{2}{|c|}{$(n=366)$} & \multicolumn{2}{|c|}{$(n=91)$} & \multicolumn{2}{|c|}{$(n=457)^{a}$} \\
\hline Current smoker & 229 & 62.6 & 2 & 2.2 & 231 & 50.6 \\
\hline Ex-smoker & 64 & 17.5 & 1 & 1.1 & 65 & 14.2 \\
\hline
\end{tabular}

${ }^{a}$ Smoking history was only available for 457 patients. 


\begin{tabular}{|c|c|c|}
\hline Variable & No. & $\%$ \\
\hline \multicolumn{3}{|l|}{ Presenting symptoms } \\
\hline Chest pain & 558 & 89.7 \\
\hline Nausea and vomiting & 441 & 70.9 \\
\hline Epigastric pain & 109 & 17.5 \\
\hline Breathlessness & 89 & 14.3 \\
\hline Dizziness & 62 & 10.0 \\
\hline Fatigue & 58 & 9.3 \\
\hline \multicolumn{3}{|c|}{ Duration of stay in hospital (days) ${ }^{a}$} \\
\hline$<8$ & 128 & 26.7 \\
\hline $8-14$ & 251 & 52.3 \\
\hline$>14$ & 101 & 21.0 \\
\hline \multicolumn{3}{|l|}{ In-hospital treatment } \\
\hline Aspirin & 562 & 90.4 \\
\hline Beta-blocker & 363 & 58.4 \\
\hline Streptokinase & 336 & 54.0 \\
\hline ACE inhibitor & 263 & 42.3 \\
\hline \multicolumn{3}{|l|}{ ECG location } \\
\hline Anterior & 389 & 62.5 \\
\hline Inferior & 203 & 32.6 \\
\hline Subendocardial & 20 & 3.2 \\
\hline Posterior & 6 & 1.0 \\
\hline Right ventricle & 4 & 0.6 \\
\hline \multicolumn{3}{|c|}{ Duration of symptoms prior to presentation (hours) ${ }^{b}$} \\
\hline$<4$ & 185 & 32.2 \\
\hline $4-6$ & 83 & 14.4 \\
\hline $7-12$ & 101 & 17.5 \\
\hline$>12$ & 207 & 35.9 \\
\hline \multicolumn{3}{|l|}{ Treatment at discharge $^{c}$} \\
\hline Aspirin & 406 & 91.6 \\
\hline Beta -blocker & 233 & 52.6 \\
\hline ACE inhibitor & 213 & 48.1 \\
\hline
\end{tabular}

${ }^{a}$ For 480 discharged patients (patients who left against medical advice were excluded); ${ }^{b}$ Data available for 576 patients; ${ }^{\circ}$ Treatment at discharge was available for 443 patients.

ACE inhibitor $=$ angiotensin converting enzyme inhibitor; $E C G=$ electrogardigraph.

fourth decade is predominantly a disease of men [2]. In the present study, more than three-quarter of patients included (75.7\%) were male (i.e. a male to female ratio $3.1: 1$ ). This is similar to the results from communities in some industrialized countries [14]. However the ratio is lower than the 6:1 ratios in studies from some other Arab countries [15].

Our results showed that the sex ratio was related to age, with the male to female ratio being 6.6: 1 in patients younger than 60 years of age and 2.1:1 in older patients. This ratio is similar to the sex ratio recorded in 2 British communities [14] and reflects the fact that women with acute ischaemic syndromes tend to be older than men with such syndromes [16]. In the present study, the ratio of the number of patients $>60$ years of age to those $\leq 60$ years was 1.0:1 in male patients and 3.3:1 in female patients
Diabetes is a major independent predictor of morbidity and mortality in acute MI [7], probably through its associations with pre-existing left ventricular dysfunction and diffuse and rapidly progressive coronary atherosclerosis [17]. The current data indicated that $48.2 \%$ of all patients hospitalized at Tripoli medical centre with acute MI had diabetes. This is higher than the $10.5 \%$ to $30.0 \%$ reported in the other studies conducted in south Asian and white patients in Britain [17] and 3 times greater than that of participants with diabetes among Saudi Arabian MI patients [15,18]. This reflects the high burden of diabetes in our population, and suggests that more aggressive strategies need to be directed towards primary prevention among this vulnerable group.

Hypertension, another well-established cardiovascular risk factor, was present in $35.7 \%$ of patients. Hypertensive individuals more frequently have symptoms preceding acute MI, probably due to ventricular hypertrophy associated with high blood pressure [5]. Women with acute ischaemic syndromes have higher rates of associated diabetes and hypertension because the protective effects of the premenopausal state can probably be overcome by these 2 potent causes of atherosclerosis [13].

The effect of cigarette smoking on the risk of MI has long been investigated and the results of one recent study suggested that cigarette smoking played the most important role in MI in individuals under the age of 36 years [19]. Smoking increases the risk of an initial cardiac event and doubles the rate of subsequent infarction and death [6]. The association between cigarette smoking and a high cholesterol level is well established [20]. This may reflect the higher intake of dietary fat and cholesterol among smokers or the metabolic effects of cigarette smoke metabolites [20]. As the number of cigarettes smoked per day increases so the cholesterol level rises in both males 
and females [20]. Our results showed that smoking was an important risk factor among Libyan male patients. Of the 366 patients in the present study group for whom smoking history was available, $17.5 \%$ were ex-smokers and $62.6 \%$ were current smokers. This is comparable with the range of current smoking history among males with acute MI found in some other studies [17]. On the other hand, in industrialized countries the range of smoking in females can be high and approach the male range [14]. However, this is quite different from the female smoking habits in our sample. Few women smoke in the Libyan community [21]. Our study showed that only 2 female patients (1.3\%) were current smokers. This is similar to the findings of another study conducted in Libya and reported elsewhere [21].

\section{Conclusion}

In view of the high inpatient mortality risk among acute MI patients in the present investigation public health planners and clinicians should be aware of the importance of early diagnosis of MI and the ensuing burden of various cardiovascular risk factors so that appropriate primary and secondary prevention strategies can be implemented.

\section{References}

1. Khot UN et al. Prevalence of conventional risk factors in patients with coronary heart disease. Journal of the American Medical Association, 2003, 290:898-904.

2. Al-Kateb $\mathrm{H}$ et al. Coronary risk factors of angiographically as sessed patients from Syria. Journal of Cardiovascular Risk, 1998, 5:31-35.

3. Roaeid RB, Kablan AA. Diabetes mortality and causes of death in Benghazi: a 5-year retrospective analysis of death certificates. Eastern Mediterranean Health Journal, 2010, 16:65-69.

4. Opie LH, Mayosi BM. Cardiovascular disease in sub-Saharan Africa. Circulation, 2005, 112:3536-3540.

5. Manfroi WC et al. Acute myocardial infarction. The first manifestation of ischemic heart disease and relation to risk factors. Arquivos Brasileiros de Cardiologia, 2002, 78:392-395.

6. Mehta RH, Eagle KA. Secondary prevention in acute myocardial infarction. British Medical Journal, 1998, 316:838-842.

7. Ribeiro DG et al. Acute myocardial infarction: predictors of mortality at a public hospital in the city of Fortaleza, Ceará state. Arquivos Brasileiros de Cardiologia, 2003, 80:614-620.

8. Wilson PW, Kannel WB. Hypertension as a risk factor for cardiac events-epidemiologic results of long-term studies. Journal of Cardiovascular Pharmacology, 1993, 21:S27-S37.

9. Grundy SM et al. Assessment of cardiovascular risk by use of multiple risk factor assessment equations. Circulation, 1999, 100:1481-1492.

10. Eagles CJ, Gulati R, Martin U. Non-pharmacological modification of cardiac risk factors: part 1. Journal of Clinical Pharmacy and Therapeutics, 1996, 21:289-296.

11. Kober $L$ et al. Influence of age on the prognostic importance of left ventricular dysfunction and congestive heart failure on long-term survival after acute myocardial infarction. American Journal of Cardiology, 1996, 78:158-162.
12. Mendelsohn ME, Karas RH. The protective effects of estrogen on the cardiovascular system. New England Journal of Medicine, 1999, 340:1801-1811.

13. Borzak S, Weaver WD. Sex and outcome after myocardial infarction: a case of sexual politics? Circulation, 2000, 102:24582459.

14. Tunstall-Pedoe $\mathrm{H}$ et al. Sex differences in myocardial infarction and coronary deaths in the Scottish MONICA population of Glasgow 1985 to 1991: presentation, diagnosis, treatment, and 28-day case fatality of 3991 events in men and 1551 events in women. Circulation, 1996, 93:1981-1992.

15. Rashed WA et al. Thrombolytic therapy in acute myocardial infarction: experience at a university hospital in Kuwait. Annals of Saudi Medicine, 1998, 18:301-304.

16. Gurwitz JH et al. Recent age-related trends in the use of thrombolytic therapy in patients who have had acute myocardial infarction. Annals of Internal Medicine, 1996, 124:283-291.

17. Wilkinson $\mathrm{P}$ et al. Comparison of case fatality in South Asian and white patients after acute myocardial infarction: observational study. British Medical Journal, 1996, 312:1330-1333.

18. Hakim JG et al. Acute myocardial infarction in a region of Saudi-Arabia-the Gizan experience. Saudi Medical Journal, 1991, 12:392-396.

19. Panagiotakos D et al. Cigarette smoking and myocardial infarction in young men and women: a case-control study. International Journal of Cardiology, 2007, 116:371-375.

20. Hebert JR, Kabat GC. Difference in dietary intake associated with smoking status. European Journal of Clinical Nutrition, 1990, 44:185-193.

21. Eldarrat $\mathrm{A}$ et al. The prevalence of self-reported halitosis and oral hygiene practices among Libyan students and office workers. Libyan Journal of Medicine, 2008, 3:170-176. 